\title{
Contemporary collecting
}

\author{
By Dr Margaret Wilson, Honorary Curator, BDA Museum, London, UK
}

$\mathrm{T}$ he museum of the British Dental Association (BDA) holds one of the largest dental collections of any museum in Europe. It holds many thousands of objects relating to the study and practice of dentistry. The museum records and collects equipment, photographic images, oral histories and stories about dentistry so that future generations can understand and appreciate how the profession evolved.

When we think of museums, it is probably natural to only think of old equipment, materials or recording outdated techniques. However, contemporary collecting of items used now or in recent history is also part of the museum's acquisition policy. It may therefore come as a surprise that although the museum has a good collection of nineteenth and early twentieth-century artefacts, there is an absence of late twentieth and twentyfirst-century items. This is a very worrying deficit considering the rapid advances in dentistry that have occurred during recent years. For example, the museum has almost a complete lack of artefacts relating to implant dentistry.

There is some good news: the BDA Museum has recently received two very important donations.

The first is an archive on tooth whitening from Dr Linda Greenwall, the highly motivated specialist dentist and internationally renowned expert in tooth whitening. Until we received her donation, the museum had next to no artefacts on bleaching teeth. Dr Greenwall's donation includes images and papers from her research, tooth whitening products, lamps and also press cuttings of the legal wrangling concerning tooth whitening. The collection includes a Philips Zoom tooth whitening lamp (Fig. 1).

The use of tooth whitening as part of minimal intervention and the huge rise in aesthetic dentistry and dental attractiveness has played a major role in contemporary

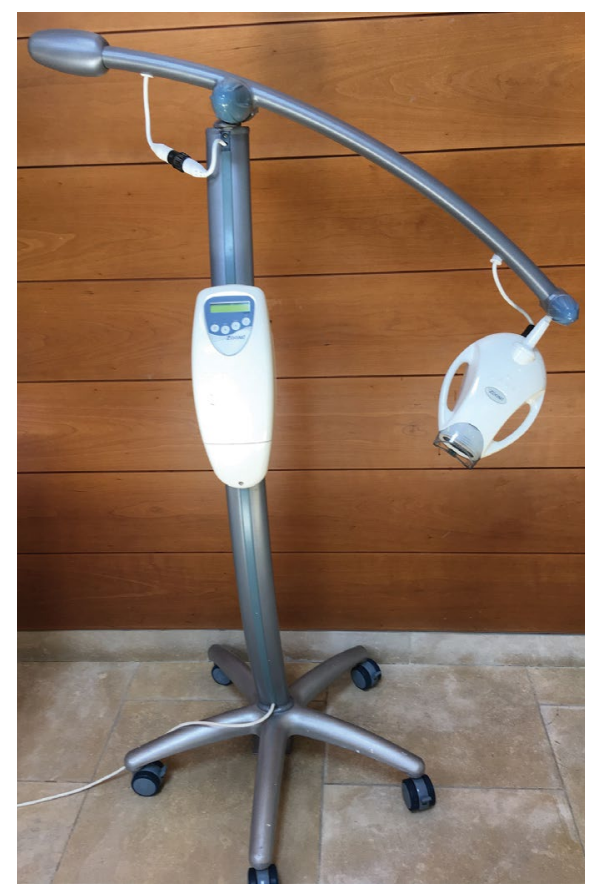

Fig. 1 Philips Zoom Lamp

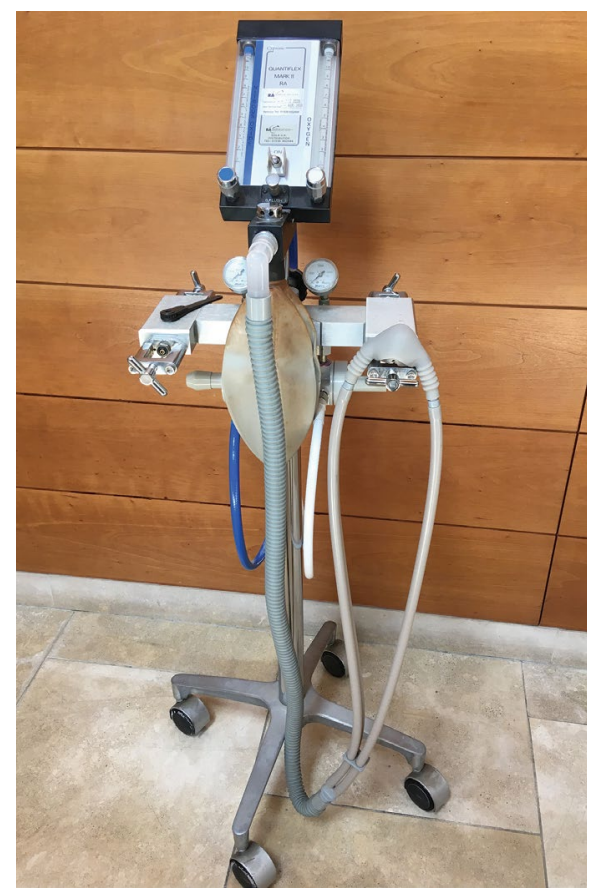

Fig. 2 Quantiflex Mark II

\section{'We need to collect these objects now so that they are available for future generations of dentists researching dental history.'}

dentistry so it is vital that this era of dentistry is recorded. We are also grateful that Dr Greenwall has donated an archive relating to the Dental Wellness Trust of which she was the founder.

The second donation was from Dr Koye Ogunro's orthodontic clinic in Fetcham. Until we received this donation, the museum had no artefacts relating to the administration of conscious sedation, referred to by some as relative analgesia. The Quantiflex Mark II is an inhalation sedation machine for delivering nitrous oxide and oxygen gases. This iconic machine is still used in the safe management of nervous child and adult dental patients (Fig. 2). It has numerous safety devices and continues to be used in hospitals, clinics and practices across the country.
Both these donations are examples of contemporary collecting and form part of the recent and current provision of dentistry in the UK. We need to collect these objects now so that they are available for future generations of dentists researching dental history.

There will continue to be developments in how dental treatment is provided and dental students starting their courses this year will be amazed by how dentistry was carried out in 2021. Or in other words: today is tomorrow's history. So, before you discard a piece of equipment, material or object from your surgery, phone us or send us an email and an image - you never know, you might have donated what may become an iconic object of twenty-firstcentury dentistry. 